\title{
Cytochrome P450 17A1 inhibitor abiraterone attenuates cellular growth of prostate cancer cells independently from androgen receptor signaling by modulation of oncogenic and apoptotic pathways
}

\author{
HANNAH GROSSEBRUMMEL ${ }^{1}$, TILMANN PETER ${ }^{1}$, ROBERT MANDELKOW ${ }^{1}$, MARTIN WEISS ${ }^{1}$, \\ DAMIAN MUZZIO ${ }^{2}$, UWE ZIMMERMANN ${ }^{1}$, REINHARD WALTHER ${ }^{3}$, FEDERICO JENSEN $^{2}$, \\ CORNELIUS KNABBE ${ }^{4}$, MAREK ZYGMUNT ${ }^{2}$, MARTIN BURCHARDT ${ }^{1}$ and MATTHIAS B. STOPE ${ }^{1}$ \\ Departments of ${ }^{1}$ Urology, ${ }^{2}$ Obstetrics and Gynaecology, ${ }^{3}$ Medical Biochemistry and Molecular Biology, \\ University Medicine Greifswald, D-17475 Greifswald; ${ }^{4}$ Institute for Laboratory and Transfusion Medicine, \\ Heart and Diabetes Center North Rhine-Westphalia, Ruhr University Bochum, D-32545 Bad Oeynhausen, Germany
}

Received September 18, 2015; Accepted October 26, 2015

DOI: 10.3892/ijo.2015.3274

\begin{abstract}
Abiraterone provides significant survival advantages in prostate cancer (PC), however, the current understanding of the molecular mechanisms of abiraterone is still limited. Therefore, the abiraterone impact on androgen receptor (AR)-positive LNCaP and AR-negative PC-3 cells was assessed by cellular and molecular analyses. The present study demonstrated, that abiraterone treatment significantly decreased cell growth, AR expression, and AR activity of AR-positive LNCaP cells. Notably, AR-negative PC-3 cells exhibited comparable reductions in cellular proliferation, associated with DNA fragmentation and pro-apoptotic modulation of $\mathrm{p} 21$, caspase-3, survivin, and transforming growth factor $\beta$ (TGF $\beta$ ). Our observations suggest that the attenuation of AR signaling is not the only rationale to explain the abiraterone anticancer activity. Abiraterone efficacy may play a more global role in PC progression control than originally hypothesized. In this regard, abiraterone is not only a promising drug for treatment of AR-negative PC stages, even more, abiraterone may represent an alternative for treatment of other malignancies besides prostate cancer.
\end{abstract}

Correspondence to: Dr Matthias B. Stope, Department of Urology, University Medicine Greifswald, Ferdinand-Sauerbruch-Strasse, Building DZ7, Room J05.10, D-17475 Greifswald, Germany

E-mail: matthias.stope@uni-greifswald.de

Abbreviations: $\mathrm{PC}$, prostate cancer; $\mathrm{TGF} \beta$, transforming growth factor $\beta$; $\mathrm{AR}$, androgen receptor; $\mathrm{Bax}, \mathrm{Bcl}-2$-associated $\mathrm{X}$ protein; TUNEL, terminal deoxynucleotidyl transferase dUTP nick end labeling

Key words: prostate cancer, abiraterone, cytochrome P450 17A1, apoptosis, cell cycle, transforming growth factor $\beta$

\section{Introduction}

Molecular factors involved in the progression of advanced prostate cancer (PC), from an initially well responding state to a castration-resistant tumor, are multifunctional but can be attributed to the capability of cell proliferation in a low androgen environment. Castration-resistant PC is clinically reflected by rising levels of prostate specific antigen (PSA) and predominantly driven by changes in androgen receptor (AR) signaling. Phenotypical alterations in AR functionality enable tumor cell growth in absence or with near undetectable concentrations of androgens. Current studies suggest that initiation and progression of PC are tightly driven by local de novo synthesis of androgens in tumor tissue and tumor environment and accessorily accompanied by extragonadal sources, as the conversion of circulating steroid precursors to testosterone and dihydrotestosterone $(1,2)$.

Within the group of new generation PC drugs, abiraterone was shown to provide significant survival advantages with modest toxicity even in post-chemotherapy settings (3). Abiraterone elicits antitumor activity by inhibiting cytochrome P450, family 17 , subfamily A, polypeptide 1 (CYP17A1) enzyme, which is critical for steroid synthesis from cholesterol. CYP17A1 studies by conversion of both pregnenolone and progesterone to $17 \alpha$-hydroxypregnenolone and $17 \alpha$-hydroxyprogesterone ( $17 \alpha$-hydroxylase activity) and by subsequent cleavage of $17 \alpha$-hydroxypregnenolone and $17 \alpha$-hydroxyprogesterone to dehydroepiandrosterone (DHEA) and androstenedione (C17,20-lyase activity) (4). Although less efficient than CYP17A1 inhibition, abiraterone also blocks some downstream enzymes of the steroid pathway (5). Additionally to blockading steroid hormones, the derangement of steroidogenic biosynthesis lowers the concentration of glucocorticoids and results in exaggerated production of mineralocorticoids (6). Moreover, clinical and preclinical studies have shown that abiraterone possesses further activities which may contribute to tumor biology 
of advanced PC. Most likely based on its steroidal structure, abiraterone has been found bound to the AR and thus competitively antagonizes subsequent AR signaling cascades, however, not as potent as pure antagonists, e.g. bicalutamide $(7,8)$. On the contrary, there are lines of evidence that abiraterone is an inducer of steroidogenic enzymes including CYP17A1 and may increase expression of steroid synthesis machinery (9-11). Our present understanding of molecular properties of abiraterone is still limited. In particular, combinatorial or sequential combinations of abiraterone with other drugs as well as the usage of abiraterone in different settings of PC remain unsolved. Due to multiplicity and complexity of recently described abiraterone effects, an inhibitory activity exclusively based on a blockade of androgen synthesis appears unlikely. With this study we assessed abiraterone effects on AR-positive and AR-negative PC cells to gain insight into the molecular mode of action.

\section{Materials and methods}

Chemicals and antibodies. Abiraterone acetate was kindly provided by Janssen-Cilag GmbH (Neuss, Germany) and was used as a $10 \mathrm{mM}$ (LNCaP cells) and $30 \mathrm{mM}$ (PC-3 cells) stock solution, respectively, with dimethyl sulfoxide (Carl Roth, Karlsruhe, Germany) as solvent. Docetaxel was purchased from Sigma-Aldrich (Munich, Germany) and was used as $10 \mu \mathrm{M}$ stock solution. Antibodies directed against the AR and the glyceraldehyde 3-phosphate dehydrogenase (GAPDH) as well as peroxidase-coupled secondary antibodies directed against mouse and rabbit were purchased from Cell Signaling Technology (Danvers, MA, USA). Antibodies specific for the transforming growth factor $\beta$ (TGF $\beta$ ) receptor type I and II were obtained from Santa Cruz Biotechnology, Inc. (Santa Cruz, CA, USA) and antibodies directed against homolog of Caenorhabditis Sma and Drosophila Mad 3 (Smad3) and Smad4 were obtained from Zymed Laboratories (San Francisco, CA, USA).

Cell culture. The PC cell lines LNCaP and PC-3 from Cell Lines Service (CLS, Heidelberg, Germany) were propagated in RPMI-1640 media supplemented with $10 \%$ fetal bovine serum, $1 \%$ sodium pyruvate, and $1 \%$ penicillin/streptomycin (all from PAN Biotech, Aidenbach, Germany) at $5 \% \mathrm{CO}_{2}$ atmosphere and $37^{\circ} \mathrm{C}$. Cells were passaged twice per week using a trypsin/ethylenediaminetetraacetic acid solution $(0.1 / 0.04 \%)$ dissolved in phosphate-buffered saline (PBS) (both from PAN Biotech). For experiments, cells were plated in poly-L-lysine (Sigma-Aldrich, Deisenhofen, Germany)-coated 24-well (proliferation assay) and 6-well [quantitative reverse transcription-polymerase chain reaction (RT-PCR), western blot analysis] cell culture plates, respectively.

Proliferation assay. Cell growth of abiraterone treated cells was examined by cell counting utilizing a CASY Cell Counter and Analyzer Model TT (Roche Applied Science, Mannheim, Germany) and compared to vehicle treated cells. Therefore, 30,000 cells/well were seeded in 24-well cell culture plates and treated as indicated. Number of living cells was determined by trypsin/ethylenediaminetetraacetic acid detachment of adherent cells and subsequent analysis. The cell suspension (100 $\mu \mathrm{l})$ was diluted in 10,000 $\mu$ l CASYton (Roche Applied Science) and analysis of $400 \mu \mathrm{l}$ dilution was performed in triplicates using a capillary of $150 \mu \mathrm{m}$ in diameter. Gate settings of 7.20/15.45 $\mu \mathrm{m}$ were used to ensure the discrimination between living cells and dead cells, as well as cellular debris.

Annexin V assay. Apoptosis detection of abiraterone-incubated PC-3 cells was performed using a FITC Annexin V Apoptosis Detection kit I (BD Bioscience, Heidelberg, Germany) as recommended by supplier instructions. After washing the cells once with PBS, $6 \times 10^{5}-1 \times 10^{6}$ cells were harvested with a cell scraper and were resuspended in $1 \mathrm{ml}$ PBS. After centrifugation and discarding the supernatant, the pellet was resuspended in binding buffer and stained with propidium iodide and FITC Annexin V for $15 \mathrm{~min}$. Data were assessed by a FACSCanto A Cytometer and were analyzed using BD FACSDiva ${ }^{\mathrm{TM}}$ software (both from BD Bioscience).

Terminal deoxynucleotidyl transferase dUTP nick end labeling (TUNEL) assay. TUNEL apoptosis analysis of abiraterone-incubated PC-3 cells was performed using the HT TiterTACS assay kit (Trevigen, Gaithersburg, MD, USA) following supplier recommendations. After indicated time-points of incubation adherent cells were detached by $0.1 \%$ trypsin/0.04\% EDTA. Data were acquired using an Infinite 200 PRO multimode reader and were analyzed using the i-control 1.9 software (both from Tecan, Männedorf, Switzerland). Unlabeled and nuclease treated samples served as negative and positive control, respectively.

Quantitative RT-PCR. Total RNA was extracted using $500 \mu \mathrm{l}$ peqGold TriFast reagent (PeqLab, Erlangen, Germany) and $50 \mu 1$ 1-bromo-3-chloropropane (Sigma-Aldrich) according to manufacturer's instructions. Prepared RNA was resuspended in diethyl pyrocarbonate (Carl Roth) treated water and RNA concentration was determined in a spectral photometer (NanoDrop 2000c; Peqlab). One microgram of total RNA was applied in RT using MMLV Reverse Transcriptase (Promega, Mannheim, Germany), Ribolock RNAse Inhibitor (Thermo Fisher Scientific, Rockford, IL, USA) and an oligo(dT) ${ }_{18}$ oligonucleotide. Subsequently, mRNA amounts were quantified by real-time PCR using the following pairs of oligonucleotides: PSA forward, 5'-CCGGAGAGCTGTGTCACCAT-3' and reverse, 5'-GTGCAGCACCAATCCACGTC-3'; caspase-3 forward, 5'-GCTCCTAGCGGATGGGTGCT-3' and reverse, 5'-GATTCCAAGGCGACGCCAAC-3'; cyclin-dependent kinase inhibitor 1 (p21) forward, 5'-TGGAGACTCTCAGGGT CGAAA-3' and reverse, 5'-GGCGTTTGGAGTGGTAGAA ATC-3', Bcl-2-associated X protein (Bax) forward, 5'-TCC CCCCGAGAGGTCTTTT-3' and reverse, 5'-CGGCCCCA GTTGAAGTTG-3'; survivin forward, 5'-TGCCCCGACGT TGCC-3' and reverse, 5'-CAGTTCTTGAATGTAGAGATGC GGT-3', ribosomal protein large P0 (RPLP0) forward, 5'-CAATGGCAGCATCTACAACC-3' and reverse, 5'-ACT CTTCCTTGGCTTCAACC-3'. Real-time PCR was carried out with SensiMix SYBR Hi-Rox (Bioline, Luckenwalde, Germany) in a CFX96 Real-Time PCR detection system (Bio-Rad Laboratories, München, Germany). For quantification, target specific signals were standardized to RPLP0 mRNA as reference. 

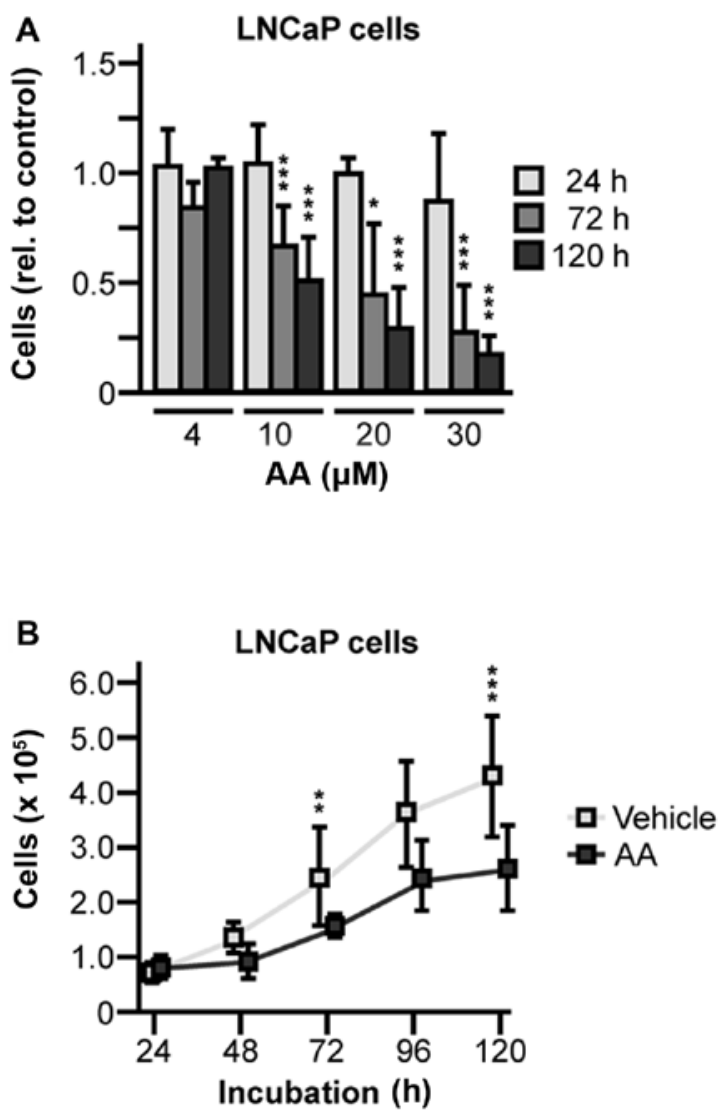

Figure 1. Abiraterone (AA) treatment attenuates cell growth of AR-positive LNCaP cells. (A) LNCaP cell were treated with vehicle or with concentrations of 4, 10, 20 and $30 \mu \mathrm{M}$ abiraterone and proliferation assays were performed after indicated times of incubation. Columns, mean; bars, \pm SD; ${ }^{*} \mathrm{P} \leq 0.05,{ }^{* *} \mathrm{P} \leq 0.01$ and ${ }^{* * *} \mathrm{P} \leq 0.001$ (compared to vehicle treated control cells). (B) $\mathrm{LNCaP}$ cells were treated with vehicle or with $10 \mu \mathrm{M}$ abiraterone for a period of time of $120 \mathrm{~h}$ and proliferation assays were performed after indicated times of incubation. Boxes, mean; bars, $\pm \mathrm{SD} ;{ }^{*} \mathrm{P} \leq 0.05,{ }^{* *} \mathrm{P} \leq 0.01$ and ${ }^{* * * *} \mathrm{P} \leq 0.001$ (total number of living cells).

Western blot analysis. Cells were lysed in buffer containing $50 \mathrm{mM}$ Tris ( $\mathrm{pH} 7.5), 150 \mathrm{mM} \mathrm{NaCl}, 10 \mathrm{mM} \mathrm{K}_{2} \mathrm{HPO}_{4}$, 5 mM EDTA, $10 \%$ glycerol, $1 \%$ Triton X-100, $0.05 \%$ sodium dodecyl sulfate, $1 \mathrm{mM} \mathrm{Na}_{3} \mathrm{VO}_{4}, 20 \mathrm{mM} \mathrm{NaF}, 0.1 \mathrm{mM}$ phenylmethylsulfonyl fluoride, $20 \mathrm{mM}$ 2-phosphoglycerate, and complete protease inhibitor cocktail (Roche Applied Science), total amount of protein was determined by using Bradford reagent (12), and equal amounts of protein were conducted to gel electrophoresis. After transfer onto a nitrocellulose membrane (GE Healthcare Europe, Freiburg, Germany) and blocking (Roti-Block; Carl Roth), protein detection was done by incubation with target specific primary antibodies followed by species specific secondary antibodies and visualized by SuperSignal West Dura Chemiluminescent Substrate (Thermo Fisher Scientific) in a ChemiDoc XRS System (Bio-Rad Laboratories). Protein signals were quantified by Image Lab 3.0 software (Bio-Rad Laboratories) and standardized to GAPDH signals as reference.

Statistical analysis. Results of at least three independent experiments were statistically analyzed. Analysis was performed using the Student's t-test with $\mathrm{P} \leq 0.05, \mathrm{P} \leq 0.01$ and $\mathrm{P} \leq 0.001$ given as significant. Data are expressed as mean $\pm \mathrm{SD}$.
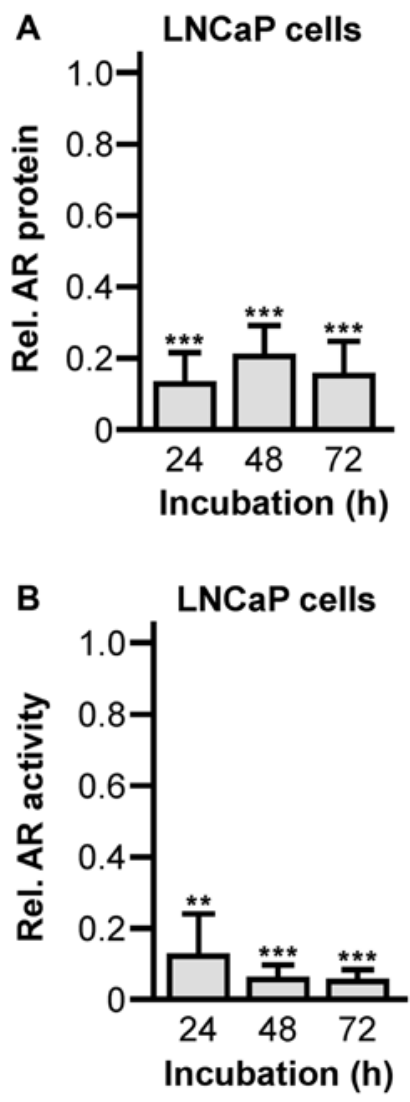

Figure 2. Abiraterone suppresses AR expression and activity in LNCaP cells (A) LNCaP cells were treated with vehicle or with $10 \mu \mathrm{M}$ abiraterone for the indicated duration and total cell extracts were subjected to western blot analyses to quantify AR protein expression normalized to GAPDH as internal reference. Columns, mean; bars, $\pm \mathrm{SD} ;{ }^{*} \mathrm{P} \leq 0.05,{ }^{* *} \mathrm{P} \leq 0.01$ and ${ }^{* * *} \mathrm{P} \leq 0.001$ (compared to vehicle treated control cells). (B) LNCaP cells were treated with vehicle or with $10 \mu \mathrm{M}$ abiraterone for the indicated duration. AR activity was assessed by quantification of the AR-dependent PSA mRNA transcription performing quantitative RT-PCR with RPLP0 mRNA as internal reference. Columns, mean; bars, $\pm \mathrm{SD} ;{ }^{*} \mathrm{P} \leq 0.05,{ }^{* *} \mathrm{P} \leq 0.01$ and ${ }^{* * *} \mathrm{P} \leq 0.001$ (compared to vehicle treated control cells).

\section{Results}

Cellular growth of AR-positive and hormone-sensitive LNCaP cells is attenuated in the presence of abiraterone by diminishing AR expression and activity. To investigate the effects of abiraterone on cellular growth of PC cells, AR-positive LNCaP cells were propagated in the presence of various concentrations of abiraterone, ranging from 4 to $30 \mu \mathrm{M}$. We found abiraterone diminished cellular growth in a concentrationdependent manner compared to vehicle treated control cells. At intermediate dosage of $10 \mu \mathrm{M}$ abiraterone, cell proliferation was inhibited to $\sim 50 \%$ after an exposure of $120 \mathrm{~h}$ (Fig. 1A). To verify theses data, growth kinetics of cells treated with $10 \mu \mathrm{M}$ abiraterone were done and statistical analysis revealed that growth suppression was significant $(72 \mathrm{~h}, 1.5$-fold, $\mathrm{P}=0.0082$; $120 \mathrm{~h}, 1.5$-fold, $\mathrm{P}=0.0010$ ) (Fig. 1B). Subsequent western blot analysis of the AR expression after $72 \mathrm{~h}$ lasting abiraterone incubation showed significantly reduced levels of AR protein (24 h, 0.13 $\pm 0.09, \mathrm{P}<0.0001 ; 48$ h, $0.20 \pm 0.10, \mathrm{P}<0.0001 ; 72 \mathrm{~h}$, $0.16 \pm 0.10, P=0.0001$ ) (Fig. 2A). The downregulation was accompanied by strongly attenuated transcriptional activity of the AR $(24 \mathrm{~h}, 0.12 \pm 0.12, \mathrm{P}=0.0096 ; 48 \mathrm{~h}, 0.06 \pm 0.04, \mathrm{P}<0.0001$; 

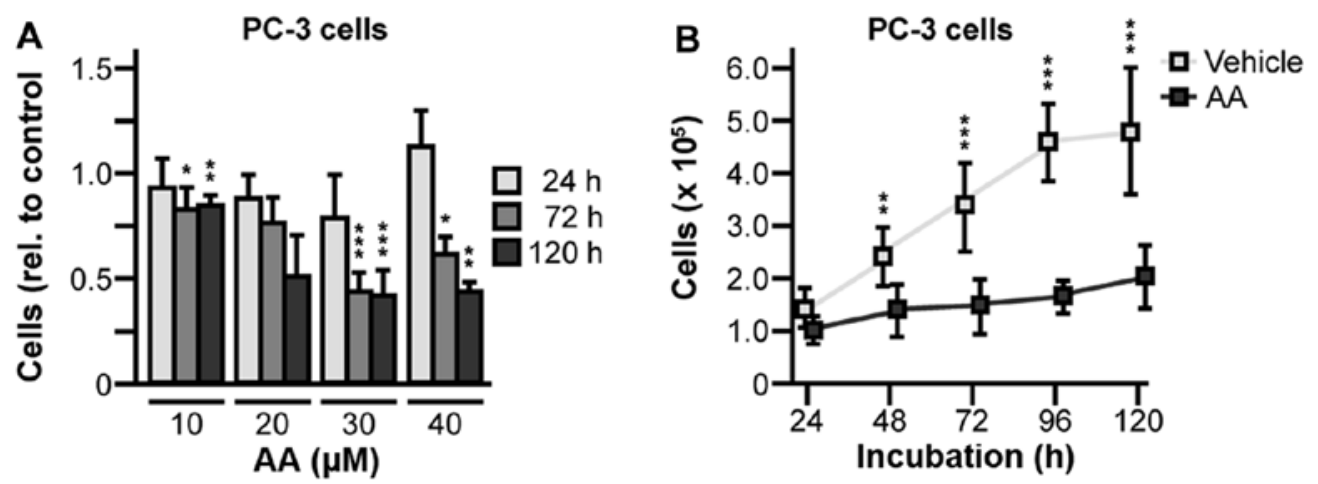

Figure 3. Abiraterone (AA) treatment attenuates cell growth of AR-negative PC-3 cells. (A) PC-3 cell were treated with vehicle or with concentrations of 10, 20,30 and $40 \mu \mathrm{M}$ abiraterone and proliferation assays were performed after indicated times of incubation. Columns, mean; bars, $\pm \mathrm{SD} ;{ }^{*} \mathrm{P} \leq 0.05,{ }^{* *} \mathrm{P} \leq 0.01$ and ${ }^{* * * *} \mathrm{P} \leq 0.001$ (compared to vehicle treated control cells). (B) PC-3 cells were treated with vehicle or with $30 \mu \mathrm{M}$ abiraterone for a period of time of $120 \mathrm{~h}$ and proliferation assays were performed after indicated times of incubation. Boxes, mean; bars, $\pm \mathrm{SD} ;{ }^{*} \mathrm{P} \leq 0.05,{ }^{* *} \mathrm{P} \leq 0.01$ and ${ }^{* * * *} \mathrm{P} \leq 0.001$ (total number of living cells).

$72 \mathrm{~h}, 0.05 \pm 0.03, \mathrm{P}<0.0001)$ (Fig. 2B), which was measured by RT-PCR quantification of the AR-dependent PSA mRNA levels.

Abiraterone inhibits cellular growth of hormone-independent $P C-3$ cells lacking AR. It was commonly hypothesized that abiraterone inhibits androgen biosynthesis and AR signaling, which is the primary antitumor activity of the drug. However, participation of AR protein and AR properties in the molecular mode of action of abiraterone have not been extensively investigated. Therefore, AR-negative PC-3 cells treated with 10 to $40 \mu \mathrm{M}$ abiraterone were analyzed and, very notably, presented growth inhibitory effects (Fig. 3A) comparable to AR-positive LNCaP cells. Further growth kinetics over $120 \mathrm{~h}$ showed statistically significant reductions of $\mathrm{PC}-3$ proliferation treated with $30 \mu \mathrm{M}$ abiraterone ( $48 \mathrm{~h}, 1.7$-fold, $\mathrm{P}=0.0026$; 72 h, 2.3 -fold, $\mathrm{P}<0.0001 ; 96$ h, 2.8-fold, $\mathrm{P}<0.0001 ; 120$ h, 2.4-fold, $\mathrm{P}<0.0001$ ) (Fig. 3B).

Abiraterone treatment of PC-3 cells initiates apoptosis due to modulation of pivotal factors in proliferation, apoptosis, and cell cycle regulation. To confirm whether the reduction of cell numbers after CAP treatment is the result of apoptotic cell death, we further examined the effects of CAP treatment by Annexin V and TUNEL assay. Previous experiments pointed to the fact that abiraterone-mediated attenuation of cellular growth can be obtained in the absence of the AR and AR-dependent signaling cascades. Therefore, we postulated interference with further regulatory pathways which may be critical for the abiraterone molecular mode of action. Primarily, we attempted to clarify whether abiraterone-dependent reduction of PC cell numbers could be associated with apoptotic cell death. Annexin V analysis in AR-negative PC-3 cells revealed a 1.09-fold and a 1.13-fold increase of apoptotic cells after 4 and $24 \mathrm{~h}$ following abiraterone treatment (Fig. 4A) compared to vehicle treated controls. We detected a 1.86 -fold and a 1.93-fold increase of dead cells after 4 and $48 \mathrm{~h}$ following abiraterone treatment (Fig. 4B). Due to the ambiguity of the results, we enforced further apoptosis detection by TUNEL assay. DNA fragment labelling by TUNEL assay showed a significant increase of DNA fragmentation in abiraterone treated PC-3 cells after 24 and 72 h $(24$ h, 1.78 $\pm 0.40, P=0.0290$;
$72 \mathrm{~h}, 3.55 \pm 1.04, \mathrm{P}=0.0133$ ) (Fig. 4C). This was comparable to DNA fragmentation of docetaxel treated control cells $(24 \mathrm{~h}$, $1.67 \pm 0.10, \mathrm{P}=0.0005$ ) (Fig. 4C).

In order to shed further light on the molecular mechanisms involved in abiraterone-induced attenuation of cell growth, we assessed the modulation of factors especially in apoptosis and cell cycle control. As shown by western blot analysis, signaling cascades of the cell growth controlling pleiotropic factor TGF $\beta$ were affected. Exposure of PC-3 cells to $30 \mu \mathrm{M}$ abiraterone significantly inhibited protein expression of both TGF $\beta$ receptor isoforms, TGF $\beta$ receptor type I $(24 \mathrm{~h}, 0.52 \pm 0.43$, $\mathrm{P}=0.0152 ; 48 \mathrm{~h}, 0.44 \pm 0.18, \mathrm{P}=0.0009 ; 72 \mathrm{~h}, 0.49 \pm 0.22$, $\mathrm{P}=0.0034)$ (Fig. 5A) and type II (24 h, 0.54 $\pm 0.08, \mathrm{P}<0.0001$; 48 h, 0.70 $\pm 0.08, \mathrm{P}=0.008 ; 72$ h, $0.50 \pm 0.24, \mathrm{P}=0.24$ ) (Fig. 5B), compared to control treated cells given as 1.0. Furthermore, the TGF $\beta$ intracellular downstream signaling proteins Smad3 ( $24 \mathrm{~h}, 0.53 \pm 0.18, \mathrm{P}=0.0096 ; 48 \mathrm{~h}, 0.49 \pm 0.12, \mathrm{P}<0.0001 ; 72 \mathrm{~h}$, $0.27 \pm 0.07, \mathrm{P}<0.0001$ ) (Fig. 5C) and Smad4 (72 h, 0.56 \pm 0.28 , $\mathrm{P}=0.0071$ ) (Fig. 5D) were significantly suppressed. Moreover, alterations of survivin, cyclin-dependent kinase inhibitor 1 (p21), caspase-3 and Bcl-2-associated X protein (Bax) mRNA levels were verified by quantitative RT-PCR and normalized to control cells. During propagation of PC-3 cells in the presence of $30 \mu \mathrm{M}$ abiraterone, the expression of the anti-apoptotic cell survival factor survivin was suppressed $(24 \mathrm{~h}, 0.33 \pm 0.40$, $\mathrm{P}=0.0438 ; 48 \mathrm{~h}, 1.01 \pm 1.05 ; 72 \mathrm{~h}, 0.25 \pm 0.08, \mathrm{P}<0.0001$ ) (Fig. 6A). Accordingly, mRNA levels of the pro-apoptotic regulators $\mathrm{p} 21$

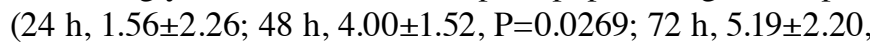
$\mathrm{P}=0.0088)$ (Fig. 6B) and caspase-3 (24 h, 5.62 $\pm 2.63, \mathrm{P}=0.0382$; 48 h, 4.08 $4.84 ; 72$ h, 1.02 \pm 0.69 ) (Fig. 6C) were significantly elevated. Notably, synthesis of the pro-oncogenic factor Bax was slightly but significantly reduced within $72 \mathrm{~h}$ of abiraterone incubation $(24 \mathrm{~h}, 1.11 \pm 0.55 ; 48 \mathrm{~h}, 1.00 \pm 0.82 ; 72 \mathrm{~h}, 0.37 \pm 0.09$, $\mathrm{P}<0.0001$ ) (Fig. 6D).

\section{Discussion}

Molecular properties of CYP17A1 as a key enzyme in androgen biosynthesis provided the rationale for development of the CYP17A1 inhibitor abiraterone. Former studies with regard to the multiple cytochrome $\mathrm{P} 450$ enzyme inhibitor ketoconazole have served as proof-of-principle: repression of 

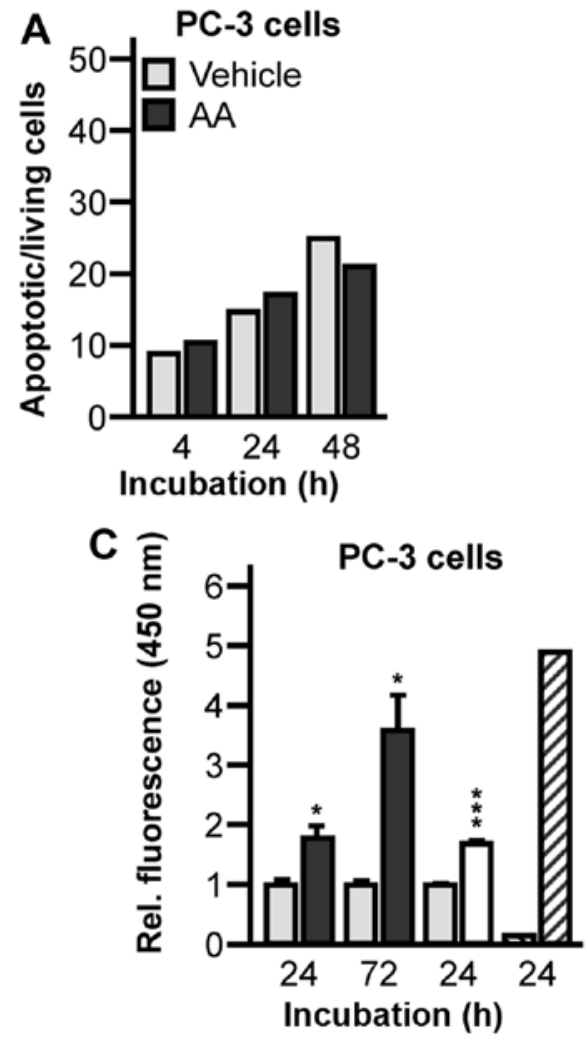

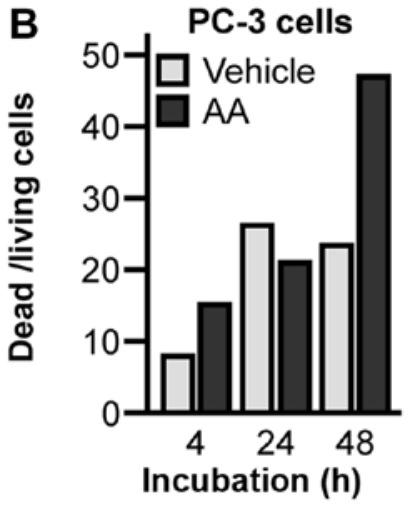

$\square$ Vehicle

AA

$\square$ Docetaxel

$\mathbf{\Delta}$ Unlabeled control

D Nuclease control

Figure 4. Abiraterone (AA) treatment is followed by induction of apoptosis. (A and B) PC-3 cells were treated with vehicle or with $30 \mu \mathrm{M}$ abiraterone for the indicated time-points and were stained with propidium iodide and FITC Annexin V. Data were assessed by a FACSCanto A Cytometer. (C) PC-3 cells were treated with vehicle or with $30 \mu \mathrm{M}$ abiraterone for the indicated time-points. Docetaxel of $10 \mathrm{nM}$ treated PC-3 cells served as control. Unlabeled control cells served as negative control and nuclease treated cells as positive control, respectively. Cells were harvested and processed by specific labeling of nuclear DNA fragmentation with a HT TiterTACS assay kit. Data are expressed as the mean \pm SD (compared and normalized to vehicle treated control cells). ${ }^{*}$ p $<0.05$ and **** $\mathrm{p}<0.001$, as determined by Student's t-test.
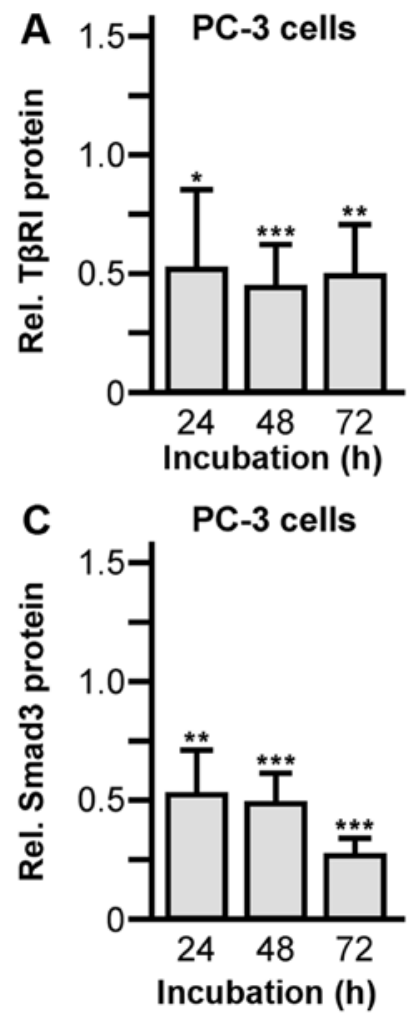
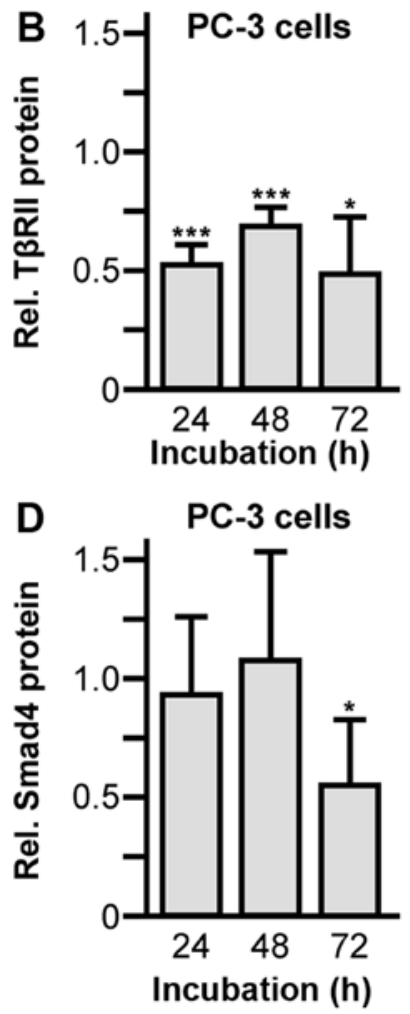

Figure 5. Abiraterone diminishes factors of the TGF $\beta$ signaling pathway. (A-D) PC-3 cells were treated with vehicle or with $30 \mu \mathrm{M}$ abiraterone for the indicated duration and total cell extracts were subjected to western blot analyses normalized to GAPDH as internal reference. (A) TGF $\beta$ receptor I; (B) TGF $\beta$ receptor II; (C) Smad3; (D) Smad4. Columns, mean; bars, $\pm \mathrm{SD} ;{ }^{*} \mathrm{P} \leq 0.05,{ }^{* *} \mathrm{P} \leq 0.01$ and ${ }^{* * * *} \mathrm{P} \leq 0.001$ (compared to vehicle treated control cells). 

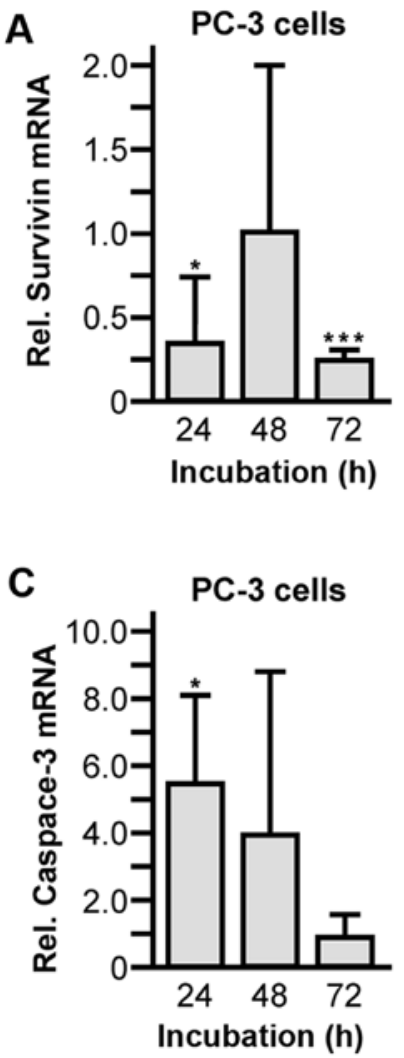
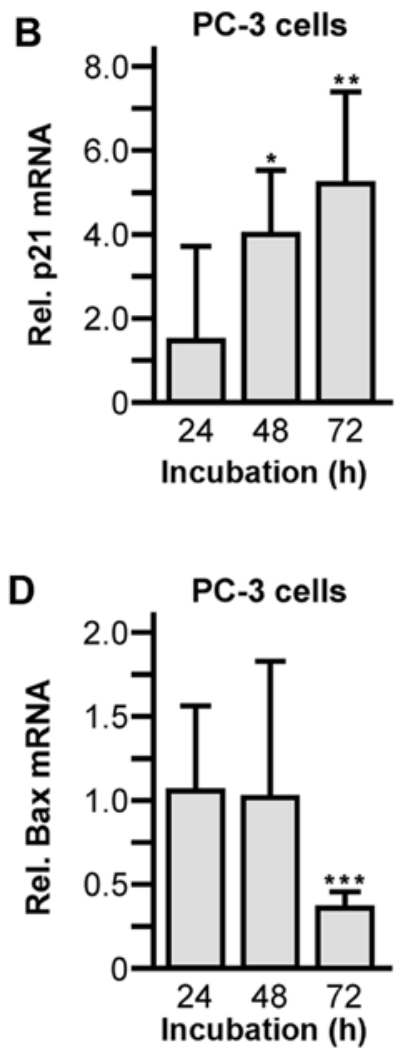

Figure 6. Abiraterone suppresses factors of apoptosis and cell cycle pathways. (A-D) PC-3 cells were treated with vehicle or with $30 \mu \mathrm{M}$ abiraterone for the indicated duration and specific transcripts were quantified by performing quantitative RT-PCR with RPLP0 mRNA as internal reference. (A) Survivin mRNA; (B) p21 mRNA; (C) caspase-3 mRNA; (D) Bax mRNA. Columns, mean; bars, $\pm \mathrm{SD}$; ${ }^{*} \mathrm{P} \leq 0.05,{ }^{* *} \mathrm{P} \leq 0.01$ and ${ }^{* * *} \mathrm{P} \leq 0.001$ (compared to vehicle treated control cells).

cytochrome P450 enzymes including CYP17A1 were shown to harbor anticancer activity in PC, however, ketoconazole administration was of minor benefit and was accompanied by significant toxicity (13). Recent studies of Brossard et al utilizing abiraterone derivates with a broad spectrum of inhibited cytochrome P450 enzymes have confirmed this hypothesis (14). Therefore, current understanding of molecular abiraterone efficacy in PC is primarily based on attenuated androgen biosynthesis/conversion and subsequent diminished AR signaling by the potent and specific inhibition of CYP17A1.

The data presented here provide evidence that abiraterone treatment resulted in significantly reduced proliferation rates even for PC cells lacking AR signaling. We previously reported that abiraterone significantly decreased the viability of AR expressing LNCaP cells most likely by the antagonistic properties of abiraterone $(7,8)$. Moreover, growth attenuation was accompanied by a dramatically diminshed AR protein expression and activity. These observations are in accordance with a study of Soifer et al, which considered downregulation of the AR in the presence of 1.0-15.0 $\mu \mathrm{M}$ abiraterone (15).

Remarkably, AR-negative PC-3 cells exhibited comparably inhibited growth characteristics in the presence of abiraterone. The applied drug concentration of $30 \mu \mathrm{M}$ corresponds to abiraterone concentrations which were determined in our study (10 $\mu \mathrm{M}$ in LNCaP cell incubation experiments) and in a study of Bruno et al $(10 \mu \mathrm{M}$ in PC-3 cell incubation experiments) (16). Notably, attenuation of PC-3 proliferation point to additional and AR-independent pathways which were targeted by abiraterone. Accordingly, further experiments suggested a broad spectrum of anti-tumor activities of abiraterone displayed by targeting regulatory factors of TGF $\beta$, apoptosis and cell cycle pathways.

Besides the numerous AR signaling events, it is well established that there are several proliferative signal cascades which are qualified to become active in PC growth, e.g. phosphatidylinositide 3-kinase (17), epidermal growth factor (18), and estrogen receptor (19) pathways. The precise role of the pleiotropic growth factor TGF $\beta$, which is also part of this multiple and fine-tuned regulatory network, is controversial. On the one hand, TGF $\beta$ has been reported to govern differentiation and anti-proliferation in non-malignant prostate epithelium as well as in early stage PC tissue. On the other hand, TGF $\beta$ signals are linked to a tumorigenic phenotype in advanced PC stages (20-23). Even though abiraterone did not affect TGF $\beta 1$ and TGF $\beta 2$ mRNA levels (data not shown), analysis of TGF $\beta$ pathway proteins revealed a clear suppression of TGF $\beta$ cascades. Abiraterone inhibited both types of TGF $\beta$ receptors, type I and II, as well as the downstream signaling molecules Smad3 and Smad4; thus, it is reasonable to hypothesize a strong reduction of TGF $\beta$ signaling by abiraterone treatment. However, since TGF $\beta$ signals play a dual role in PC reflected by its opposing properties of pro- and anti-oncogenic effects, it is difficult to estimate the TGF $\beta$-dependent impact of abiraterone. Though, elevated serum levels of TGF $\beta$ have been shown to predict tumor recurrence and metastasis, and the PC cells became less responsive to TGF $\beta$ growth inhibition in later stages of PC $(20,24)$, therefore, abiraterone efficacy was probably due to attenuation of TGF $\beta$-dependent oncogenic 
signal cascades. However, these results further exemplify the difficulties of interpretation of TGF $\beta$ pathways in PC cell biology and may suggest further investigations in this field.

Chemotherapy widely exerts its anticancer effect by triggering apoptotic mechanisms of tumor cells. A primary regulator of apoptosis is the tumor suppressor p53, which plays a key role in cell cycle control, genomic stability, and apoptosis. Due to a frame shift within the p53 gene, PC-3 cells express a truncated and therefore inactive form of the protein $(25,26)$, however, the induction of apoptosis pathways in absence of p53 as a response to drug treatment has been extensively described (27-29). Notwithstanding, in PC-3 cells lacking functional p53 the initiation of intrinsic apoptosis pathway factors occurs in the presence of abiraterone. Increased DNA fragmentation as determined by TUNEL assay, as well as downregulation of the cell survival factor survivin and elevated levels of the cell cycle inhibitor p21 and the effector caspase-3 clearly indicated an execution of apoptotic mechanisms. These data confirm former studies which have shown that anticancer drugs affect the biosynthesis of these intrinsic apoptotic factors in PC-3 cells (28,30-32). Surprisingly, our results could not be definitely verified by Annexin $\mathrm{V}$ staining. Since externalisation of Annexin V to the outer plasma membrane is a very early effect in apoptosis, it could be speculated that Annexin V signals have already expired before the first selected time point. However, it is notable that Annexin V staining of PC-3 cells failed also previously (33). Curiously, we monitored significantly reduced levels of pro-apoptotic Bax after $72 \mathrm{~h}$ of abiraterone incubation. This finding is not consistent with earlier reports in which Bax has been shown being drug-induced in PC-3 cells (28). The intrinsic apoptosis pathway is controlled by a balance of pro-apoptotic (e.g. Bax, p21 and caspase-3) and anti-apoptotic (e.g. survivin) factors. Apoptosis in the absence of p53, however, appears complex. Therefore, differing cell death cascades compared to the classical intrinsic apoptosis pathways by interfering with other regulatory pathways may occur. For instance, there have been reports that apoptosis induced by the hypoxia response system can provoke a downregulation of Bax in cancer cells $(34,35)$.

Taken together, our observations suggest that abirateronemediated attenuation of AR signals is not the only rationale to explain anticancer activity. Besides an expected inhibition of LNCaP cell growth by targeting the AR, very notably, abiraterone comparably inhibited proliferation of AR-negative PC-3 cells. Thus, abiraterone's molecular mode of action is proposed to be mediated through an accessory inhibition of pro-oncogenic TGF $\beta$ signals and through the alteration of apoptotic factors.

Experimental and preclinical data continue to enlarge our understanding of abiraterone molecular mode of action and facilitate the opportunity to improve $\mathrm{PC}$ treatment regimes as well as to overcome resistance to abiraterone. Interestingly, current data showed no, or no detectable expression of CYP17A1 enzyme in LNCaP and PC-3 cell lines (35) and, in this context, abiraterone efficacy may play a more global role in PC progression control than originally hypothesized. Consequently, abiraterone is not only a promising drug for treatment of AR-negative PC stages, even more, abiraterone may represent a therapeutical alternative for treatment of other malignancies besides PC.

\section{Acknowledgements}

The authors thank Anne Brandenburg and Katja Wittig for excellent technical assistance. Parts of this study were supported by a grant of the Gerhard Domagk grant of the University Medicine Greifswald, Greifswald, Germany. The compound abiraterone acetate was kindly provided by the Janssen-Cilag GmbH, Neuss, Germany.

\section{References}

1. Labrie F, Luu-The V, Lin SX, Simard J, Labrie C, El-Alfy M, Pelletier $G$ and Bélanger A: Intracrinology: Role of the family of 17 beta-hydroxysteroid dehydrogenases in human physiology and disease. J Mol Endocrinol 25: 1-16, 2000.

2. Piao YS, Wiesenfeld P, Sprando R and Arnold JT: TGF $\beta 1$ alters androgenic metabolites and hydroxysteroid dehydrogenase enzyme expression in human prostate reactive stromal primary cells: Is steroid metabolism altered by prostate reactive stromal microenvironment? J Steroid Biochem Mol Biol 138: 206-213, 2013.

3. de Bono JS, Logothetis CJ, Molina A, Fizazi K, North S, Chu L, Chi KN, Jones RJ, Goodman OB Jr, Saad F, et al; COU-AA-301 Investigators: Abiraterone and increased survival in metastatic prostate cancer. N Engl J Med 364: 1995-2005, 2011.

4. Miller WL: Steroidogenic enzymes. In: Disorders of the Human Adrenal Cortex. Flück CE and Miller WL (eds). Karger, Basel, pp1-18, 2008.

5. Yin L and Hu Q: CYP17 inhibitors - abiraterone, C17,20-lyase inhibitors and multi-targeting agents. Nat Rev Urol 11: 32-42, 2014.

6. Pia A, Vignani F, Attard G, Tucci M, Bironzo P, Scagliotti G, Arlt W, Terzolo $M$ and Berruti A: Strategies for managing ACTH dependent mineralocorticoid excess induced by abiraterone. Cancer Treat Rev 39: 966-973, 2013.

7. Richards J, Lim AC, Hay CW, Taylor AE, Wingate A, Nowakowska K, Pezaro C, Carreira S, Goodall J, Arlt W, et al: Interactions of abiraterone, eplerenone, and prednisolone with wild-type and mutant androgen receptor: A rationale for increasing abiraterone exposure or combining with MDV3100. Cancer Res 72: 2176-2182, 2012

8. Harshman LC and Taplin ME: Abiraterone acetate: Targeting persistent androgen dependence in castration-resistant prostate cancer. Adv Ther 30: 727-747, 2013.

9. Stanbrough M, Bubley GJ, Ross K, Golub TR, Rubin MA, Penning TM, Febbo PG and Balk SP: Increased expression of genes converting adrenal androgens to testosterone in androgenindependent prostate cancer. Cancer Res 66: 2815-2825, 2006.

10. Cai C, Chen S, Ng P, Bubley GJ, Nelson PS, Mostaghel EA, Marck B, Matsumoto AM, Simon NI, Wang H, et al: Intratumoral de novo steroid synthesis activates androgen receptor in castration-resistant prostate cancer and is upregulated by treatment with CYP17A1 inhibitors. Cancer Res 71: 6503-6513, 2011.

11. Mostaghel EA, Marck BT, Plymate SR, Vessella RL, Balk S, Matsumoto AM, Nelson PS and Montgomery RB: Resistance to CYP17A1 inhibition with abiraterone in castration-resistant prostate cancer: Induction of steroidogenesis and androgen receptor splice variants. Clin Cancer Res 17: 5913-5925, 2011.

12. Bradford MM: A rapid and sensitive method for the quantitation of microgram quantities of protein utilizing the principle of protein-dye binding. Anal Biochem 72: 248-254, 1976.

13. Small EJ, Baron AD, Fippin L and Apodaca D: Ketoconazole retains activity in advanced prostate cancer patients with progression despite flutamide withdrawal. J Urol 157: 1204-1207, 1997.

14. Brossard D, Zhang Y, Haider SM, Sgobba M, Khalid M, Legay R, Duterque-Coquillaud M, Galera P, Rault S, Dallemagne P, et al: $\mathrm{N}$-substituted piperazinopyridylsteroid derivatives as abiraterone analogues inhibit growth and induce pro-apoptosis in human hormone-independent prostate cancer cell lines. Chem Biol Drug Des 82: 620-629, 2013.

15. Soifer HS, Souleimanian N, Wu S, Voskresenskiy AM, Collak FK, Cinar B and Stein CA: Direct regulation of androgen receptor activity by potent CYP17 inhibitors in prostate cancer cells. J Biol Chem 287: 3777-3787, 2012. 
16. Bruno RD, Gover TD, Burger AM, Brodie AM and Njar VC: 17alpha-Hydroxylase/17,20 lyase inhibitor VN/124-1 inhibits growth of androgen-independent prostate cancer cells via induction of the endoplasmic reticulum stress response. Mol Cancer Ther 7: 2828-2836, 2008.

17. Wong KK, Engelman JA and Cantley LC: Targeting the PI3K signaling pathway in cancer. Curr Opin Genet Dev 20: 87-90, 2010.

18. Traish AM and Morgentaler A: Epidermal growth factor receptor expression escapes androgen regulation in prostate cancer: A potential molecular switch for tumour growth. Br J Cancer 101: 1949-1956, 2009.

19. Nakamura Y, McNamara K and Sasano H: Estrogen receptor expression and its relevant signaling pathway in prostate cancer: A target of therapy. Curr Mol Pharmacol 5: 392-400, 2012.

20. Steiner MS and Barrack ER: Transforming growth factor-beta 1 overproduction in prostate cancer: Effects on growth in vivo and in vitro. Mol Endocrinol 6: 15-25, 1992.

21. Danielpour D: Functions and regulation of transforming growth factor-beta (TGF-beta) in the prostate. Eur J Cancer 41: 846-857, 2005.

22. Zhu B and Kyprianou N: Transforming growth factor beta and prostate cancer. Cancer Treat Res 126: 157-173, 2005.

23. Stope MB, Rönnau C, Schubert T, Staar D, Bradl J, Ziegler P, Streitbörger A, Kroeger N, Zimmermann U, Walther R, et al Transforming growth factor $\beta$ in prostate cancer: Cellular effects and basic molecular mechanisms. Urologe A 52: 378-383, 2013 (In German).

24. Shariat SF, Kattan MW, Traxel E, Andrews B,Zhu K, Wheeler TM and Slawin KM: Association of pre- and postoperative plasma levels of transforming growth factor beta(1) and interleukin 6 and its soluble receptor with prostate cancer progression. Clin Cancer Res 10: 1992-1999, 2004

25. Carroll AG, Voeller HJ, Sugars L and Gelmann EP: p53 oncogene mutations in three human prostate cancer cell lines. Prostate 23 123-134, 1993

26. van Bokhoven A, Varella-Garcia M, Korch C, Johannes WU, Smith EE, Miller HL, Nordeen SK, Miller GJ and Lucia MS; Bokhoven van A: Molecular characterization of human prostate carcinoma cell lines. Prostate 57: 205-225, 2003.

27. Coxon JP, Oades GM, Kirby RS and Colston KW: Zoledronic acid induces apoptosis and inhibits adhesion to mineralized matrix in prostate cancer cells via inhibition of protein prenylation. BJU Int 94: 164-170, 2004
28. Huang F, Yang Z, Yu D, Wang J, Li R and Ding G: Sepia ink oligopeptide induces apoptosis in prostate cancer cell lines via caspase-3 activation and elevation of Bax/Bcl-2 ratio. Mar Drugs 10: 2153-2165, 2012.

29. Raja Singh P, Arunkumar R, Sivakamasundari V, Sharmila G, Elumalai P, Suganthapriya E, Brindha Mercy A, Senthilkumar K and Arunakaran J: Anti-proliferative and apoptosis inducing effect of nimbolide by altering molecules involved in apoptosis and IGF signalling via PI3K/Akt in prostate cancer (PC-3) cell line. Cell Biochem Funct 32: 217-228, 2014.

30. Muenchen HJ, Poncza PJ and Pienta KJ: Different docetaxel-induced apoptotic pathways are present in prostate cancer cell lines LNCaP and PC-3. Urology 57: 366-370, 2001.

31. Fares M, Abou-Seri SM, Abdel-Aziz HA, Abbas SE, Youssef MM and Eladwy RA: Synthesis and antitumor activity of pyrido [2,3-d]pyrimidine and pyrido[2,3-d] [1,2,4]triazolo[4,3-a] pyrimidine derivatives that induce apoptosis through $\mathrm{G} 1$ cellcycle arrest. Eur J Med Chem 83: 155-166, 2014.

32. Hsu JL, Liu SP, Lee CC, Hsu LC, Ho YF, Huang HS and Guh JH: A unique amidoanthraquinone derivative displays antiproliferative activity against human hormone-refractory metastatic prostate cancers through activation of LKB1-AMPK-mTOR signaling pathway. Naunyn Schmiedebergs Arch Pharmacol 387: 979-990, 2014

33. Weiss M, Gümbel D, Hanschmann EM, Mandelkow R, Gelbrich N, Zimmermann U, Walther R, Ekkernkamp A, Sckell A, Kramer A, et al: Cold atmospheric plasma treatment induces anti-proliferative effects in prostate cancer cells by redox and apoptotic signaling pathways. PLoS One 10: e0130350, 2015.

34. Erler JT, Cawthorne CJ, Williams KJ, Koritzinsky M, Wouters BG, Wilson C, Miller C, Demonacos C, Stratford IJ and Dive C: Hypoxia-mediated down-regulation of Bid and Bax in tumors occurs via hypoxia-inducible factor 1-dependent and -independent mechanisms and contributes to drug resistance. Mol Cell Biol 24: 2875-2889, 2004.

35. Zhang H, Sun L, Xiao X, Xie R, Liu C, Wang Y, Wei Y, Zhang H and Liu L: Krüppel-like factor 8 contributes to hypoxia-induced multidrug resistance in gastric cancer cells. Cancer Sci 105: $1109-1115,2014$ 